\title{
Broadly tunable mid-infrared VECSEL for multiple components hydrocarbon gas sensing
}

\section{Journal Article}

\section{Author(s):}

Rey, Julien M.; Fill, Matthias; Felder, Ferdinand; Sigrist, Markus W.

Publication date:

2014-12

Permanent link:

https://doi.org/10.3929/ethz-b-000087825

Rights / license:

In Copyright - Non-Commercial Use Permitted

Originally published in:

Applied Physics B 117(3), https://doi.org/10.1007/s00340-014-5911-1 


\title{
Broadly tunable mid-infrared VECSEL for multiple components hydrocarbon gas sensing
}

\author{
J. M. Rey • M. Fill • F. Felder • M. W. Sigrist
}

Received: 12 June 2014/ Accepted: 7 August 2014/Published online: 19 August 2014

(C) Springer-Verlag Berlin Heidelberg 2014

\begin{abstract}
A new sensing platform to simultaneously identify and quantify volatile $\mathrm{C} 1$ to $\mathrm{C} 4$ alkanes in multicomponent gas mixtures is presented. This setup is based on an optically pumped, broadly tunable mid-infrared vertical-external-cavity surface-emitting laser (VECSEL) developed for gas detection. The lead-chalcogenide VECSEL is the key component of the presented optical sensor. The potential of the proposed sensing setup is illustrated by experimental absorption spectra obtained from various mixtures of volatile hydrocarbons and water vapor. The sensor has a sub-ppm limit of detection for each targeted alkane in a hydrocarbon gas mixture even in the presence of a high water vapor content.
\end{abstract}

\section{Introduction}

The identification and quantification of mixtures of gaseous hydrocarbons is of great interest for many industrial applications. Among them is the analysis of $\mathrm{C} 1$ to $\mathrm{C} 4$ alkanes (i.e., methane, ethane, propane, and butanes) in gas mixtures used in the petrochemical industry. Such analysis

J. M. Rey · M. Fill · M. W. Sigrist $(\bowtie)$

Laser Spectroscopy and Sensing Laboratory, Institute for

Quantum Electronics, ETH Zurich, Otto-Stern-Weg 1,

8093 Zurich, Switzerland

e-mail: sigristm@phys.ethz.ch

\section{J. M. Rey}

Institute of Applied Mathematics and Physics, Zurich University of Applied Sciences, Technikumsstrasse 9, 8401 Winterthur, Switzerland

M. Fill · F. Felder

Camlin Technologies Switzerland, Technoparkstrasse 1,

8005 Zurich, Switzerland is important in a variety of applications, including natural/ biogas gas composition analysis, energy content measurement (BTU measurement), fuel blending and control, optimization of power generation (fuel cells, gas turbines), and monitoring of hydrocarbon leaks at pipelines and refineries [1-4].

Mainly due to the small tuning range of current infrared laser modules around $3,000 \mathrm{~cm}^{-1}(3.3 \mu \mathrm{m})$, gas sensors based on infrared laser technology mostly restrict their application to small molecules (e.g., methane) and to a single target molecule per device. Analyzing hydrocarbon mixtures using infrared lasers is a complicated task since their spectra are heavily overlapping. The presence of water vapor and its associated optical absorption further complicates this task. To derive the actual gas composition from the measured optical absorption spectrum, a large and continuous tuning range coupled with a fast tuning capability of the mid-infrared laser source is desired. A large tuning range allows the measurement of multiple target compounds (e.g., $\mathrm{C} 1$ to $\mathrm{C} 4$ hydrocarbons) and to analyze them with a single laser source. For narrow molecular lines (e.g., methane), a larger number of absorption lines is recorded, while the whole absorption band of larger molecules (e.g., propane and butane) can be accessed as well [5]. Furthermore, the broad emission range allows the recording of not only the absorption lines of the targeted hydrocarbons, but also of a large portion of the background absorption. This leads to a much better selectivity and robustness against possible interfering gas species.

Today's infrared light sources around $3,000 \mathrm{~cm}^{-1}$ include blackbody emitters, nonlinear optical converters [6-10], interband (ICL) [11-13] or quantum cascade lasers (QCL) [14, 15], distributed feedback diode lasers (DFB) $[16,17]$, and more recently mid-IR vertical-external-cavity surface-emitting lasers (VECSELs) [18-20]. Blackbody 
emitters have a low spectral density, and nonlinear optical converters like optical parametric oscillators (OPOs) and difference frequency generation (DFG) are of high cost, bulky, and complicated to set up. The tuning range of DFB lasers is by a factor of 50 smaller compared to mid-IR VECSELs. Broadband-tunable ICLs/QCLs use an external cavity, resulting in a higher complexity and price.

In this work, a sensing platform to simultaneously identify and quantify volatile $\mathrm{C} 1$ to $\mathrm{C} 4$ alkanes in multicomponent gas mixtures is presented. The source is a midIR VECSEL with emphasis put on the extension of the tuning range around $3.3 \mu \mathrm{m}$. The developed system is evaluated using mixtures of the target volatile hydrocarbons and water vapor.

\section{Experimental arrangement}

\subsection{VECSEL}

The VECSEL [18-20] is based on narrow band gap IV-VI semiconductors (lead chalcogenides) and is pumped by a $1.55-\mu \mathrm{m}$ diode laser. The laser consists of a flat PbEuTe/ EuTe bottom mirror, a IV-VI-based active layer, and an external top mirror. The active layer comprises $\mathrm{PbSe}$ quantum wells in $\mathrm{PbSrSe}$ host material. The materials employed enable emission wavelengths in the $2,200-3,300 \mathrm{~cm}^{-1}$ range at room temperature (RT). The top mirror based on six $\mathrm{SiO}_{2} / \mathrm{Si}$ pairs is movable in the vertical direction by a piezoelectric actuator, which shifts the emission wavelength by more than $\pm 75 \mathrm{~cm}^{-1}$ around the center wavelength. Scan frequencies up to the $\mathrm{kHz}$ regime are feasible, since tuning is achieved purely mechanically. Due to the short cavity length of typically $<50 \mu \mathrm{m}$, the emission occurs in a single longitudinal $\mathrm{TEM}_{00}$ mode with quasi-perfect Gaussian shape. The VECSEL is thermoelectrically stabilized and operates at RT with a pulsed output power of $>10 \mathrm{~mW}_{\mathrm{p}}$. The pulses are $5 \mathrm{~ns}$ long with a pulse frequency up to $150 \mathrm{kHz}$. The laser used for the presented work is tunable from $2,950 \mathrm{~cm}^{-1}$ to $3,100 \mathrm{~cm}^{-1}$ and is ideal to detect all main features of the $\mathrm{C} 1-\mathrm{C} 4$ alkanes, including baseline.

\subsection{Optical gas sensing}

The gas sensing setup is depicted in Fig. 1. It consists of the VECSEL presented above generating the tunable midIR beam, which is collimated with a $\mathrm{CaF}_{2}$ lens (focal length: $20 \mathrm{~mm}$ ), polarized (IGP 227, Cambridge Physical Sciences), and split with a $\mathrm{CaF}_{2}$ plate into two beams. The reference beam passes through a reference cell (length: $50 \mathrm{~mm}$ ) filled with $\mathrm{CH}_{4}$ (ca. $2 \% \mathrm{vv}$ ) diluted in $\mathrm{N}_{2}$ at 980 mbar. The signal beam is sent to a homemade Herriot

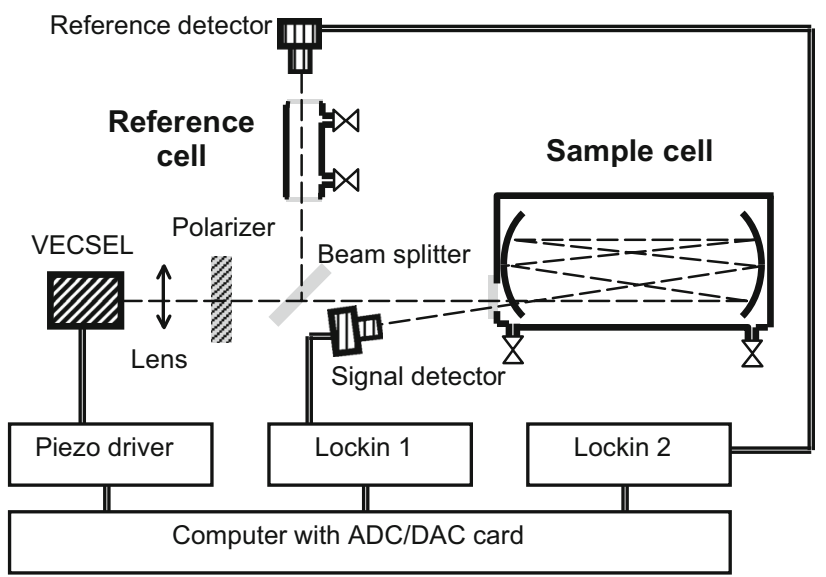

Fig. 1 Schematic representation of the sensing setup

[21] multipass cell (total pathlength: $13.35 \mathrm{~m}$ ) containing the sample under investigation. Both the signal and the reference beams are detected with thermoelectrically cooled MCT detectors (PDI 2TE-4, Vigo System). The pulse repetition rate of the VECSEL is $93.77 \mathrm{kHz}$, and the detector signals are demodulated at this frequency using two lock-in amplifiers (SR830, Stanford Research) with a 1 -ms time constant. The lock-in outputs are recorded in a computer by a DAQ card (PCI-6052E, National Instruments). The VECSEL wavelength is tuned by applying a voltage ramp $(0-100 \mathrm{~V})$ on the VECSEL piezo element. This ramp is generated by the analog output of the DAQ card amplified by a piezo driver (SQV 1/500, Piezomechanik). Each ramp is generated within $2 \mathrm{~s}$, and 2,000 points are collected from each detector during each ramp. The reference beam and the reference cell are used to calibrate the VECSEL emission wavelength by recording the position of methane absorption lines. Owing to the high stability of the VECSEL output intensity, no intensity normalization is used except dividing the measured signal with a spectrum of the sample cell filled with pure $\mathrm{N}_{2}$. All measurements are taken at atmospheric pressure (980 mbar) and room temperature (295 K).

Various gas mixtures are generated by diluting $\mathrm{N}_{2}$ (purity 5.0) with certified reference gas mixtures of methane, ethane, propane, and butane in $\mathrm{N}_{2}$. The dilution process is conducted with a mass flow controller (Serie800, Sierra). Water vapor is added to the gas mixtures by bubbling the gas through liquid water and determining the resulting water content with a capacitive humidity meter (HMI-31, Vaisala).

\section{Results and discussion}

Figure 2 presents individual spectra of methane, ethane, propane, butane, and water vapor recorded with the 
VECSEL-based setup. Each spectrum is averaged hundred times, and the total recording time is thus $2 \mathrm{~s} \times 100=200 \mathrm{~s}$. These spectra represent reference spectra that are used in the following to fit and quantify spectra of unknown composition. The laser linewidth is determined by deconvoluting the measured methane spectrum, resulting in a laser linewidth (FWHM) of $1.3 \mathrm{~cm}^{-1}$. This linewidth is larger than one of the other laser sources in the $3,000 \mathrm{~cm}^{-1}$ range [6]; nevertheless, it is small enough to successfully record methane spectra at atmospheric pressure and thus more than sufficient to measure heavier hydrocarbons.

The gas concentration of a sample is obtained by fitting (least square fit) its measured absorption spectrum with the reference spectra presented in Fig. 2. Increasing the acquisition time permits to reduce the noise and the residual sum of squares (RSS) of the fit. Figure 3 presents the RSS of the fit as a function of the total acquisition time for methane $(20 \mathrm{ppm})$ in nitrogen. The RSS reaches a minimum after 40-s acquisition time. A 20-s acquisition time represents a good trade-off between the acquisition speed and RSS.

Various gas concentrations for each target gas have been investigated, and Fig. 4 depicts the measured (i.e., determined after fitting the measured spectra) versus the set gas concentrations. The solid line in the graphs has a slope of one and thus represents the case of a perfect measurement. The vertical error bars represent the $\pm 1 \sigma$ (standard deviation) range obtained from successive measurements. The horizontal error bars correspond to the estimated errors associated with the mass flow controller and the gas purity. Since Fig. 4 shows a linear behavior with a slope close to one, the limit of detection for the various investigated hydrocarbon gases is obtained from the standard deviation of the fitted concentration in pure $\mathrm{N}_{2}$. This limit of detection is $0.3 \mathrm{ppm}$ for each of the investigated hydrocarbons diluted in pure nitrogen.

A main advantage of the large tuning range of the VECSEL is the ability to simultaneously measure multiple hydrocarbons. In Fig. 5, spectra of two mixtures of methane, ethane, and propane are shown. Fitting the measured spectra with the reference spectra allows the determination of the individual gas concentrations. For such gas mixtures of hydrocarbons, the limit of detection is around $0.5 \mathrm{ppm}$ for each gas component depending on the actual gas composition.

In many practical applications of hydrocarbons sensing, various other gases are also present in the sample under investigation. Among them, carbon dioxide $\left(\mathrm{CO}_{2}\right)$, oxygen $\left(\mathrm{O}_{2}\right)$, nitrogen $\left(\mathrm{N}_{2}\right)$, and water vapor $\left(\mathrm{H}_{2} \mathrm{O}\right)$ are the most often encountered ones yet only $\mathrm{CO}_{2}$ and $\mathrm{H}_{2} \mathrm{O}$ vapor are infrared-active molecules. Since water vapor exhibits the most interfering potential, its influence on the

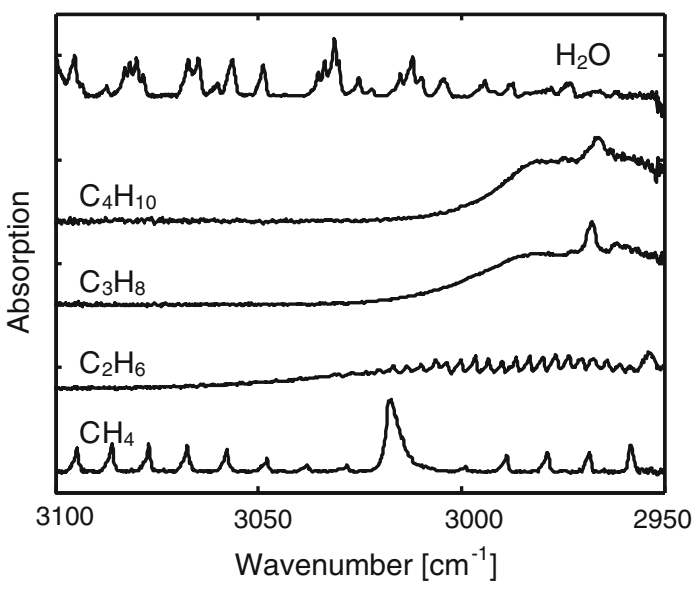

Fig. 2 Methane $\left(\mathrm{CH}_{4}\right)$, ethane $\left(\mathrm{C}_{2} \mathrm{H}_{6}\right)$, propane $\left(\mathrm{C}_{3} \mathrm{H}_{8}\right)$, butane $\left(\mathrm{C}_{4} \mathrm{H}_{10}\right)$, and water vapor $\left(\mathrm{H}_{2} \mathrm{O}\right)$ spectra measured with the VECSEL-based setup. All spectra are averaged over 100 scans (total acquisition time: $200 \mathrm{~s}$ ) and used as reference spectra (see text). The spectra are shifted vertically for better clarity

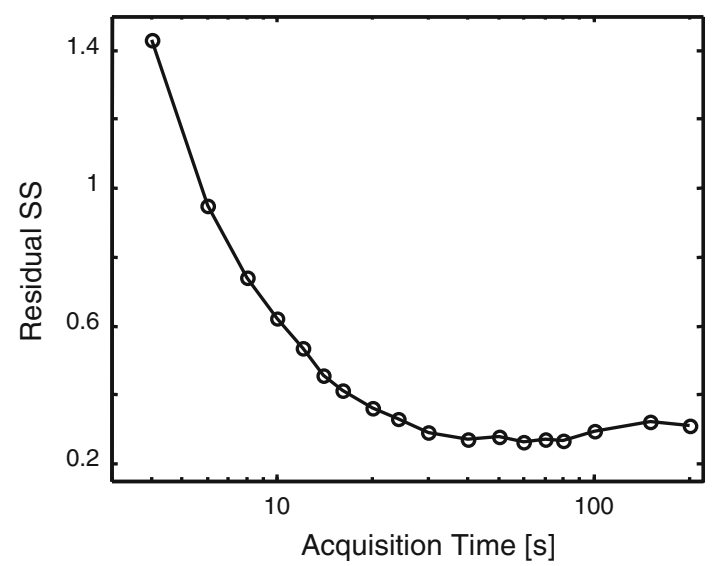

Fig. 3 Residual sum of squares [RSS, i.e., $\left.\Sigma\left(\mathrm{Abs}_{\text {fitted }}-\mathrm{Abs}_{\text {measured }}\right)^{2}\right]$ versus total spectrum acquisition time for methane $(20 \mathrm{ppm})$ in nitrogen

determination of the hydrocarbons content is further investigated. A spectrum of the three lighter hydrocarbons in the presence of water $(1.7 \% \mathrm{vv}, 70 \%$ relative humidity) is shown in Fig. 6. The presence of water causes stronger optical absorption and for certain wavelengths buries the spectra of the hydrocarbons. However, the broad tuning range of the laser allows collecting spectral information at wavelengths where water interferences are low enough to efficiently derive the concentrations of all targeted hydrocarbons. In the presence of water vapor, the limit of detection for each of the various hydrocarbons investigated increases to about $0.6 \mathrm{ppm}$ depending on the exact gas composition. This limit of detection is only approximately two times worse than that for dilution in pure nitrogen thanks to the large tuning range of the VECSEL. 
Fig. 4 Experimentally determined concentration versus set gas concentration. The line in the graphs has a slope of one and thus represents the case of a perfect sensor behavior. The vertical and horizontal error bars represent the \pm 1 standard deviation $(\sigma)$ range
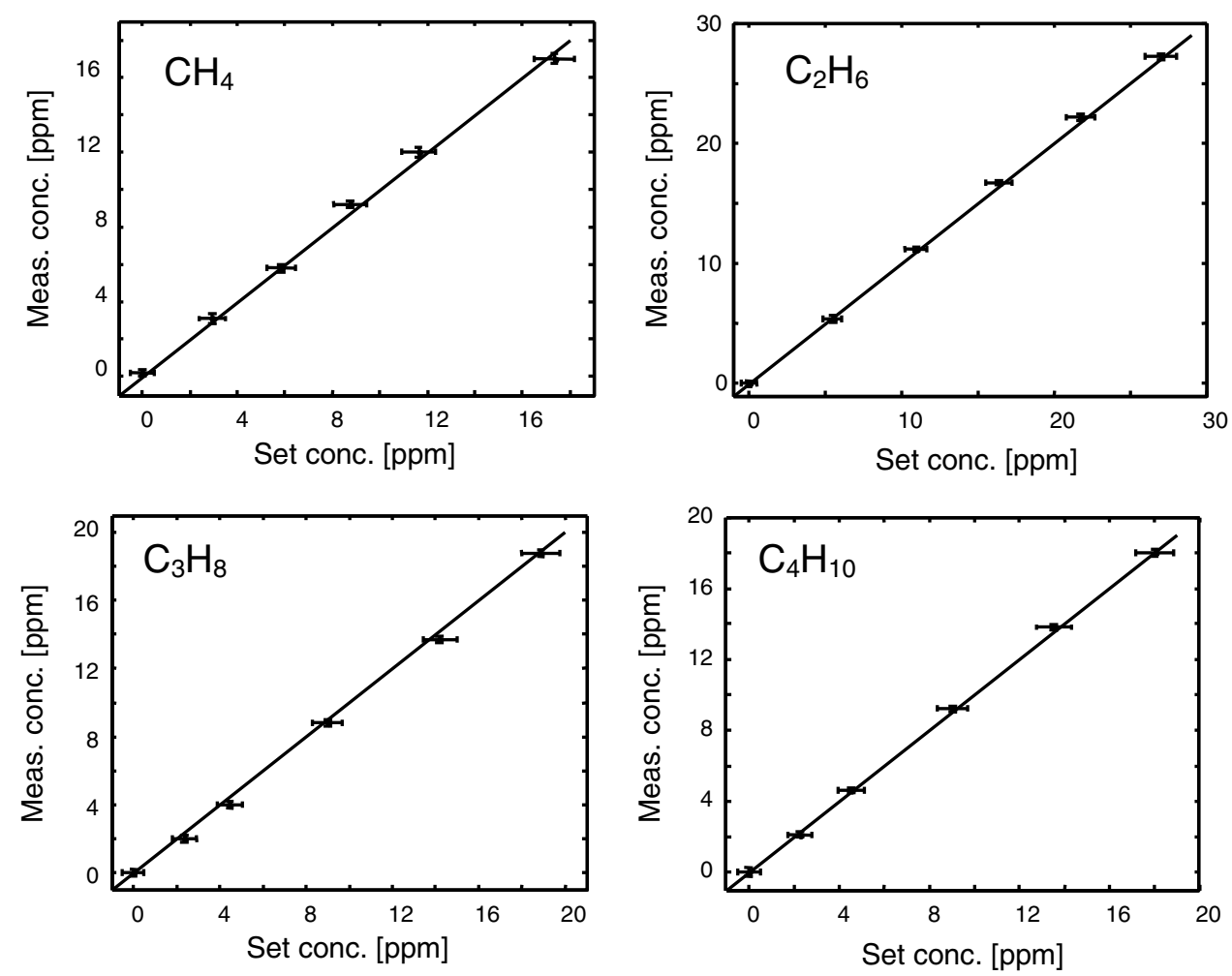

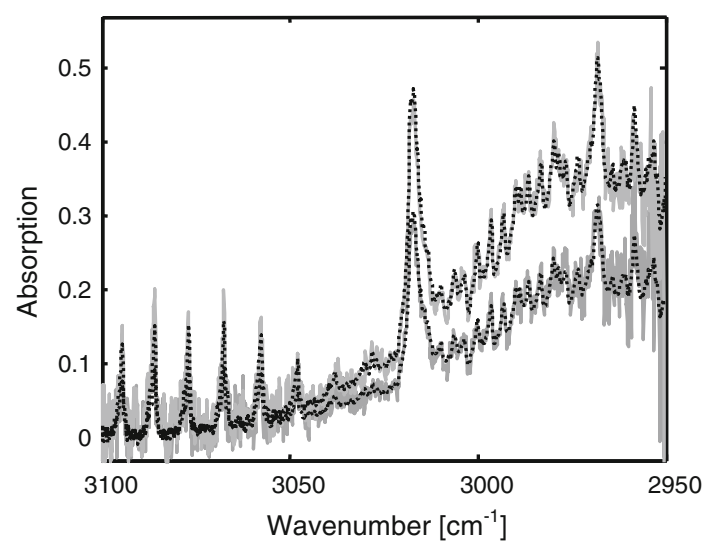

Fig. 5 Measured spectra (gray lines) of methane, ethane, and propane mixtures. The upper line corresponds to $23 \mathrm{ppm}$ of $\mathrm{CH}_{4}$, $24 \mathrm{ppm}$ of $\mathrm{C}_{2} \mathrm{H}_{6}$, and $19 \mathrm{ppm}$ of $\mathrm{C}_{3} \mathrm{H}_{8}$; the lower line to $12 \mathrm{ppm}$, $13 \mathrm{ppm}$, and $10 \mathrm{ppm}$, respectively. The dotted lines show the fitted lines. The spectra are averaged over 10 scans (total acquisition time: $20 \mathrm{~s})$

\section{Conclusion}

Using a multipass absorption cell and the mid-IR VECSEL, the absorption spectra of the targeted $\mathrm{C} 1$ to $\mathrm{C} 4$ hydrocarbons, water vapor, and mixtures thereof have been recorded over $150 \mathrm{~cm}^{-1}$ within $2 \mathrm{~s}$. Averaging over 10 spectra leads to a sub-ppm limit of detection for all investigated hydrocarbons even in the presence of a high water content.

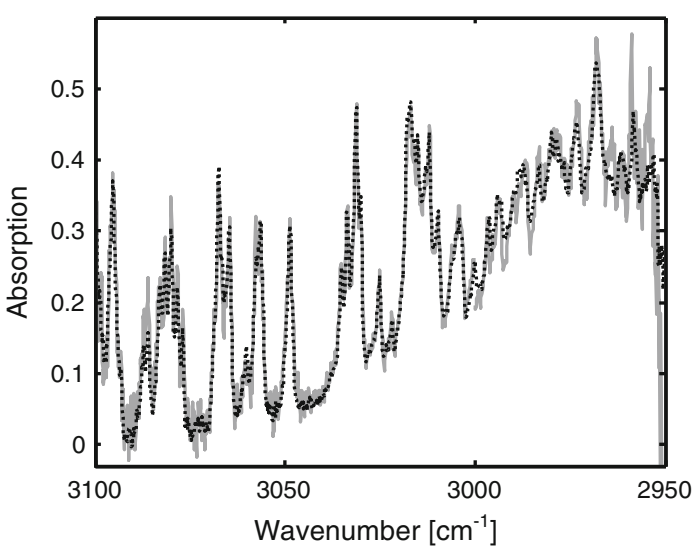

Fig. 6 Measured spectrum (gray lines) of a mixture of methane, ethane, propane, and water vapor. The concentrations are 23, 24, $20 \mathrm{ppm}$, and $1.7 \% \mathrm{vv}$, respectively. The black dotted line shows the fitted line. The spectrum is averaged over 10 scans (total acquisition time: $20 \mathrm{~s})$

The broad and fast tuning range of the mid-IR VECSEL is the key component of this optical gas sensor. The broad tuning range allows reducing optical interferences and deriving the individual target gas concentration even in complex gas mixtures. The fast tuning of the laser permits a high sensing rate especially if a narrow tuning range or a moderate sensitivity is required. The setup described in this work is promising for the identification and quantification of mixtures of gaseous hydrocarbons in many research and 
industrial applications including online monitoring in industrial processes.

Acknowledgments The financial support by KTI/CTI from the Swiss government is greatfully acknowledged.

\section{References}

1. X. Gao, H. Fan, T. Huang, X. Wang, J. Bao, X. Li, Spectrochimica Acta Part A 65, 133-138 (2006)

2. P. Bryce, P. Jax, J. Fang, Oil Gas J. 100, 53-59 (2002)

3. W. Chew, P. Sharratt, Anal. Methods 2, 1412-1438 (2010)

4. D.J. Bramford, D.J. Cook, S.J. Sharpe, A.D. van Pelt, Proceedings of the Optical Society of America Topical Meeting on Lasers to Chemical, Security and Environmental Analysis (LACSEA 2006), Incline Village (Nevada/USA), Feb 6-10 (2006), Paper PDP11

5. J. Jágerská, B. Tuzson, H. Looser, A. Bismuto, J. Faist, H. Prinz, L. Emmenegger, Appl. Opt. 52, 4613-4619 (2013)

6. I. T. Sorokina, K. L. Vodopyanov (eds.), "Solid-state midinfrared laser sources" topics in applied physics, vol. 89, Springer-Verlag, Berlin Heidelberg, 2003

7. M. Gianella, M.W. Sigrist, Appl. Opt. 50, A11-A19 (2011)

8. D.D. Arslanov, M. Spunei, J. Mandon, S.M. Cristescu, S.T. Persijn, F.J.M. Harren, Laser Photonics Rev. 7, 188-206 (2013)

9. A. Borsutzky, J.A. L. Huillier, in Optical parametric oscillators, ed. by F. Träger. Springer handbook of lasers and optics, 2nd edn (Springer, 2012), ch. 11.9
10. M. W. Sigrist, H. Wächter, M. Gianella, in Generation of coherent mid-infrared radiation by difference-frequency mixing, ed. F. Träger, "Springer handbook of lasers and optics", 2nd edn (Springer, 2012), ch. 11.10

11. W.W. Bewley, C.L. Canedy, C.S. Kim, M. Kim, C.D. Merritt, J. Abell, I. Vurgaftman, J.R. Meyer, Opt. Express 20, 20894 (2012)

12. A. Bauer, M. Dallner, M. Kamp, S. Höfling, L. Worschech, A. Forchel, Opt. Eng. 49, 111117 (2010)

13. M. Kim, C.L. Canedy, W.W. Bewley, C.S. Kim, J.R. Lindle, J. Abell, I. Vurgaftman, J.R. Meyer, Appl. Phys. Lett. 92, 191110 (2008)

14. S. Riedi, A. Hugi, A. Bismuto, M. Beck, J. Faist, Appl. Phys. Lett. 103, 031108 (2013)

15. N. Bandyopadhyay, Y. Bai, S. Tsao, S. Nida, S. Slivken, M. Razeghi, Appl. Phys. Lett. 101, 241110 (2012)

16. L. Naehle, S. Belahsene, M. von Edlinger, M. Fischer, G. Boissier, P. Grech, G. Narcy, A. Vicet, Y. Rouillard, J. Koeth, L. Worschech, Electron. Lett. 47, 46-47 (2011)

17. K. Krzempek, R. Lewicki, L. Nähle, M. Fischer, J. Koeth, S. Belahsene, Y. Rouillard, L. Worschech, F.K. Tittel, Appl. Phys. B 106, 251-255 (2012)

18. M. Fill, P. Debernardi, F. Felder, H. Zogg, Appl. Phys. Lett. 103, 201120 (2013)

19. M. Rahim, A. Khiar, M. Fill, F. Felder, H. Zogg, Electron. Lett. 47, 1037-1039 (2011)

20. M. Fill, A. Khiar, M. Rahim, F. Felder, H. Zogg, J. Appl. Phys. 109, 093101 (2011)

21. D. Herriott, R. Kompfner, H. Kogelnik, Appl. Opt. 3, 523-526 (1964) 